\title{
Occurrence of nutrients and plant hormones (cytokinins and IAA) in the water fern Salvinia molesta during growth and composting
}

\author{
Georgina D. Arthur ${ }^{\mathrm{a}}$, Wendy A. Stirk ${ }^{\mathrm{a}, *}$, Ondřej Novák ${ }^{\mathrm{b}}$, \\ Petr Hekera ${ }^{\mathrm{c}}$, Johannes van Staden ${ }^{\mathrm{a}}$ \\ ${ }^{a}$ Research Centre for Plant Growth and Development, School of Biological and Conservation Sciences, University of \\ KwaZulu-Natal Pietermaritzburg, Private Bag X01, Scottsville 3209, South Africa \\ ${ }^{\mathrm{b}}$ Laboratory of Growth Regulators, Palacký University \& Institute of Experimental Botany AS CR, \\ Slechtiteli 11, 78371 Olomouc, Czech Republic \\ ${ }^{\mathrm{c}}$ Department of Ecology, Palacký University, tr. Svobody 26, 78371 Olomouc, Czech Republic \\ Received 10 August 2006; received in revised form 3 April 2007; accepted 12 May 2007
}

\begin{abstract}
The aquatic fern Salvinia molesta is classified as an invasive, noxious weed in southern Africa. It has rapid growth and forms a thick mat in slow moving water bodies. It is hypothesized that $S$. molesta is a suitable candidate to promote as an organic fertilizer. The aims of this study were to determine the mineral content as well as the cytokinin and auxin content in $S$. molesta. The release of these compounds into the culture medium and upon decomposition of the air-dried plant matter was also determined. Minerals detected in the fresh plant material were $\mathrm{N}>\mathrm{K}>\mathrm{P}>\mathrm{Ca}>\mathrm{Mg}>\mathrm{Fe}>\mathrm{Na}>\mathrm{Cu}>\mathrm{Zn}$ while $\mathrm{Cd}, \mathrm{Pb}$ and $\mathrm{Ni}$ were below the level of detection. The mineral concentrations changed after 14 days decomposition with there being an increase in $\mathrm{Ca}, \mathrm{Mg}$ and $\mathrm{Fe}$ and a decrease in $\mathrm{K}$. Sixteen isoprenoid cytokinins were detected in the plant material (total concentration $81.62 \mathrm{pmol} \mathrm{g}^{-1} \mathrm{DW}$ ) while only four cytokinins occurred at a greatly reduced concentration in the culture medium (4.31 pmol $500 \mathrm{ml}^{-1}$ medium). The material that had been composted for 14 days showed a $17 \%$ reduction in cytokinin concentration (67.96 $\mathrm{pmol} \mathrm{g}^{-1} \mathrm{DW}$ ) compared to the plant material. Run-off, termed leachate, collected during the composting experiment also had high amounts of cytokinin-like activity measured using the soybean callus bioassay. This activity peaked on day 7 of the composting experiment, indicating a rapid release of cytokinin-like compounds. IAA occurred in much higher concentrations than the cytokinins in the plant material $\left(393.6 \mathrm{pmol} \mathrm{g}^{-1} \mathrm{DW}\right)$ while very little IAA was detected in the culture medium $\left(30.8 \mathrm{pmol} \mathrm{g}^{-1} \mathrm{DW}\right)$. IAA concentrations were much lower in the composted material $\left(148.1 \mathrm{pmol} \mathrm{g}^{-1} \mathrm{DW}\right)$ with a $62 \%$ loss being recorded compared to the plant material. No auxin-like activity was measured using the mungbean rooting bioassay in the leachate collected at the start of the composting experiment. However, the leachate collected on days 7 and 14 had biological activity indicating that auxin-like compounds were released from $S$. molesta upon decomposition.
\end{abstract}

(C) 2007 Elsevier B.V. All rights reserved.

Keywords: Auxins; Culture medium; Cytokinins; Decomposition; Mineral content; Salvinia molesta

Abbreviations: BA, benzyladenine; BA9G, benzyladenine-9-glucoside; BAR, benzyladenosine; BAR5MP, benzyladenosine-5' -monophosphate; Ca, calcium; Cd, cadmium; Cu, copper; $c \mathrm{Z}$, cis-zeatin; $c$ ZOG, cis-zeatin-O-glucoside; $c \mathrm{ZR}$, cis-zeatin riboside; $c$ ZR5MP, cis-zeatin riboside-5'-monophosphate; $c$ ZROG, $c i s$-zeatin riboside-O-glucoside; DHZ, dihydrozeatin; DHZOG, dihydrozeatin-O-glucoside; DHZ9G, dihydrozeatin-9-glucoside; DHZR, dihydrozeatin riboside; DHZR5MP, dihydrozeatin riboside-5' -monophosphate; DHZROG, dihydrozeatin riboside- $O$-glucoside; Fe, iron; IAA; indole-3-acetic acid; IBA, indole-3-butyric acid; iP, isopentenyladenine; iP9G, isopentenyladenine-9-glucoside; iPR, isopentenyladenosine; iPR5MP, isopentenyladenosine-5' -monophosphate; K, potassium; Mg, magnesium; $\mathrm{N}$, nitrogen; $\mathrm{Na}$, sodium; $\mathrm{Ni}$, nickel; $\mathrm{P}$, phosphorus; $\mathrm{Pb}$, lead; $t \mathrm{Z}$, trans-zeatin; $t \mathrm{ZOG}$, trans-zeatin- $O$-glucoside; $t \mathrm{Z} 9 \mathrm{G}$, trans-zeatin-9-glucoside; $t \mathrm{ZR}$, trans-zeatin riboside; $t$ ZR5MP, trans-zeatin riboside-5' -monophosphate; $t$ ZROG, trans-zeatin riboside- $O$-glucoside; $Z \mathrm{n}$, zinc

* Corresponding author. Tel.: +2733260 5130; fax: +27332505897.

E-mail address: stirk@ukzn.ac.za (W.A. Stirk). 


\section{Introduction}

Owing to high energy costs, increased fertilizer costs and increasing concern over the adverse effects of long term use of agro-chemicals on soil productivity and environmental quality, there is now considerable interest in the use of renewable organic fertilizers. Biofertilizers have the advantages of being an inexpensive, renewable resource that is non-polluting, providing a source of nutrients, vitamins and growth substances. They also improve soil structure and fertility by increasing the organic matter content and improving the water holding capacity of the soil (Wagner, 1997).

The nitrogen-fixing water fern Azolla has been successfully used as a biofertilizer in China and other Asian countries as well as in South America and Africa for many years. Azolla is able to fix atmospheric nitrogen due to the symbiotic relationship with the nitrogen-fixing cyanobacterium Anabaena azollae found in the dorsal leaf cavity of Azolla (see refs. in Lejeune et al., 1999). Beneficial effects of Azolla used as a biofertilizer in rice paddies and other dry-land crops such as wheat and vegetable crops include increased crop productivity, improved soil porosity and higher organic matter content (Lumpkin and Plucknett, 1980; Wagner, 1997). The beneficial effects are not caused by elevated nitrogen levels alone but also by the release of other nutrients, hormones, vitamins and other growth-promoting substances (Pedurand and Reynaud, 1987; Wagner, 1997).

Plant growth regulators play an important role in plant growth and development and can produce many desirable effects in crops. For example, the use of Seaweed Concentrates where the active ingredients have been identified as cytokinins and auxins (Stirk et al., 2004), is a well-established practice in agriculture. Their application influences many physiological processes and results in an improved root system, increased growth and yield, increased nutrient absorption and mobilization, increased resistance to stress and disease and retardation of senescence (Crouch and van Staden, 1994). Thus, if plants selected for use as biofertilizers contained nutrients as well as hormones, specifically cytokinins and auxins, they would have additional beneficial effects on the crops.

The water fern Salvinia molesta (Salviniales), commonly called the "kariba weed" is a free-floating aquatic plant which forms large expanses of thick mats in slow moving water bodies. It is a sterile hybrid introduced from South America and reproduces only by vegetative fragmentation (Henderson and Cilliers, 2002). The run-off of nutrients from fertilizers used in agriculture and the slowing of rivers by dams and weirs have created ideal conditions for its growth (Hill and Cilliers, 1999) and it is now classed as an invasive, noxious weed in southern Africa (Schelpe and Anthony, 1986; Burrows, 1990). It causes numerous problems such as reduced quality of drinking water, an increase in siltation of rivers and dams, reduced water surface for recreational use, clogging of irrigation systems and reduced water flow in irrigation canals. The thick mats also provide an ideal breeding place for carriers of malaria and bilharzia (Hill and Cilliers, 1999; Henderson and Cilliers, 2002).

It is hypothesized that $S$. molesta is a good candidate to promote as an organic fertilizer and growth biostimulant as it grows quickly on natural water bodies, is available throughout the year and requires little processing. It can be easily harvested by mechanical means (Mansor, 1996). The harvesting of S. molesta would also contribute towards its control in natural water systems. Thus the aims of this study were to quantify the mineral content as well as the cytokinin and auxin concentrations in $S$. molesta and to determine if these compounds are released upon decomposition.

\section{Material and methods}

\subsection{Plant material and experimental design}

S. molesta D.S. Mitchell was collected from a pond in the Botanical Gardens of the University of KwaZulu-Natal Pietermaritzburg and transferred to a bucket filled with 101 tap water supplemented with Chemicult, a commercial fertilizer containing macro- and micro-nutrients used in hydroponic systems. The fern grew vigorously, providing a stock of young, healthy and clean plants for the experiment. Young S. molesta plants were transferred into a large plastic container filled with 701 water supplemented with $140 \mathrm{~g}$ Chemicult. Due to transpiration and evaporation, it was necessary to replenish the medium with 151 water and Chemicult mixture on days 5 and 21 . The average minimum and maximum temperatures in the green house where S. molesta was grown during the experiment were $19^{\circ} \mathrm{C}$ and $28^{\circ} \mathrm{C}$, respectively. $S$. molesta was harvested on day 31 . A portion of this material was freeze-dried and ground into powder. The culture medium was also collected as 51 units, filtered with Whatman No. 1 filter paper and dried down under vacuum at $35{ }^{\circ} \mathrm{C}$.

The remaining plant material was air-dried $(2 \mathrm{~kg})$ and placed in a wooden bin $\left(8 \times 10^{-2} \mathrm{~m}^{3}\right)$ in a green house for the composting experiment. Water (11) was immediately poured over the plant material and the run-off collected in a tray placed beneath the wooden bin. This was referred to as the leachate. The average temperature of the compost, monitored by placing three thermometers in the decomposing plant material, was $25^{\circ} \mathrm{C}$. On days 7 and 14, 11 water was poured over the compost and leachate collected in the tray. The leachate was filtered with Whatman No. 1 filter paper and dried down under vacuum at $35^{\circ} \mathrm{C}$. The experiment was terminated on day 14 . The remains of the decomposed $S$. molesta were freeze-dried and ground into powder.

\subsection{Quantification of mineral elements}

Plant and composted material were analysed for their mineral content. Samples for nitrogen analysis were mineralized using sulphuric acid and a selenium catalyse (Kjeltabs) in a mineralization apparatus (Tecator Digestion System, Tecator, Sweden). Nitrogen estimation was performed in a Kjeltec Distilling Unit (System 1002) according to the manufacturer's procedure. All other mineral elements were analysed in $500 \mathrm{mg}$ samples which were mineralized in a mixture of $3 \mathrm{ml}$ nitric acid and $2 \mathrm{ml}$ hydrogen peroxide using a Microwave Digestion Unit (Plazmatronika, Poland; Parosa and Reszke, 1995). Phosphorus was determined 
by VIS spectrophotometry (DR 2000, HACH, USA) and all other elements by atomic absorption spectroscopy (Avanta $\Sigma$, GBC, Australia) according to the parameters listed in Table 1. Unspecific absorption was corrected using deuterium lamps (Antanasopoulos, 1996).

\subsection{Analysis for cytokinin-like activity}

The plant $(2$ reps $\times 4.5 \mathrm{gDW})$ and composted material ( 2 reps $\times 4.5 \mathrm{~g} \mathrm{DW})$ were extracted with $100 \mathrm{ml} 80 \%$ ethanol for $24 \mathrm{~h}$ at $10^{\circ} \mathrm{C}$. The extracts were briefly sonnicated and then filtered with Whatman No. 1 filter paper, rinsed with a further $100 \mathrm{ml} 80 \%$ ethanol and dried down under vacuum at $35^{\circ} \mathrm{C}$. The plant extracts, compost extracts, culture medium $(2$ reps $\times 51$ culture medium) and the compost leachates collected on days 0,7 and $14(1 \mathrm{rep} \times 250 \mathrm{ml})$ were partially purified using the method described by Dobrev and Kamínek (2002) where each sample was redissolved in $3 \mathrm{ml} \mathrm{80 \%} \mathrm{ethanol} \mathrm{and} \mathrm{passed} \mathrm{through}$ an activated Sep-Pak ${ }^{\circledR}$ Plus $\mathrm{C}_{18}$ (SPE) cartridge. The eluent was collected and dried under vacuum. The samples were redissolved in $5 \mathrm{ml} 1 \mathrm{M}$ formic acid and loaded onto an activated Oasis ${ }^{\circledR}$ MCX (150 mg/6 cc) cartridge. The cytokinin-like compounds were eluted from the cartridge using $5 \mathrm{ml} 0.35 \mathrm{M} \mathrm{NH}_{4} \mathrm{OH}$ in water followed by $5 \mathrm{ml} 0.35 \mathrm{M} \mathrm{NH}_{4} \mathrm{OH}$ in $60 \%$ methanol. These two fractions were combined and dried down. The extracts were resuspended in $2.5 \mathrm{ml} 80 \%$ ethanol and strip loaded onto Whatman No. 1 chromatography paper and developed in a descending manner in isopropanol:ammonia:water $(10: 1: 1, \mathrm{v} / \mathrm{v} / \mathrm{v})$ until the solvent front had moved approximately $30 \mathrm{~cm}$. After drying at $60{ }^{\circ} \mathrm{C}$ for $24 \mathrm{~h}$, the chromatograms were divided into 10 equal $R_{\mathrm{f}}$ zones and placed in individual flasks. These were assayed for cytokinin-like activity using the soybean callus bioassay (Miller, 1965).

Modified Millers solidified media (excluding the kinetin) was added to the flasks containing the cut-up chromatograms. Three pieces of approximately $1 \mathrm{mg} 3$-4-week-old soybean callus (Glycine max cv acme) were placed in each flask under sterile conditions. The callus grew for 28 days in continuous low light conditions $\left(1 \mu \mathrm{mol} \mathrm{m}^{-2} \mathrm{~s}^{-1}\right)$ at $24{ }^{\circ} \mathrm{C}$ after which the callus was weighed. A triplicate set of kinetin standards was included where kinetin was added to the medium at various concentrations (1, 5,10 and $\left.50 \mu \mathrm{g} \mathrm{l}^{-1}\right)$ as well as a control in which no kinetin was added to the medium.

\subsection{Analysis for auxin-like activity}

The dried, powdered $S$. molesta plant material ( 2 reps $\times$ $4.5 \mathrm{~g} \mathrm{DW})$ and the composted material $(2$ reps $\times 4.5 \mathrm{~g} \mathrm{DW})$ were extracted with $80 \%$ ethanol as described in Section 2.2. Auxin-like activity was determined using the mungbean rooting assay described by Crouch and van Staden (1991). The plant extracts, compost extracts, culture medium $(2$ reps $\times 51$ culture medium) and compost leachates collected on days 0,7 and $14(1 \mathrm{rep} \times 250 \mathrm{ml})$ were each resuspended in $100 \mathrm{ml}$ distilled water. These were further diluted with distilled water as follows: 1:1, 1:4, 1:9, 1:19, 1:49 and 1:99 to give four replicates of $20 \mathrm{ml}$ for each dilution. An IBA dilution series $\left(10^{-3}\right.$ to $10^{-7} \mathrm{M}$ ) was prepared as a standard and distilled water was used as a control. Five 10-day-old mungbean (Vigno mungo L.) cuttings were placed in each vial for $6 \mathrm{~h}$ in a growth chamber at $25^{\circ} \mathrm{C}$ and light intensity of $160 \mu \mathrm{mol} \mathrm{m}^{-2} \mathrm{~s}^{-1}$. The mungbeans were then rinsed in distilled water and placed in clean vials containing water and grown at $25^{\circ} \mathrm{C}$ in a $16 / 8 \mathrm{~h}$ light/dark regime with a light intensity of $160 \mu \mathrm{mol} \mathrm{m}^{-2} \mathrm{~s}^{-1}$. After 10 days, the number of roots was recorded.

\subsection{Cytokinin and IAA identification and quantification}

Cytokinins and IAA in the plant material, composted material and the culture medium were analysed using a modified protocol described by Novák et al. (2003). Freeze-dried samples were extracted in ice-cold $70 \%$ ethanol (v/v) and deuterium labelled standards added, each at 5 pmol per sample to check recovery during purification and to validate determination. The cytokinin standards were $\left[{ }^{2} \mathrm{H}_{5}\right] t \mathrm{Z},\left[{ }^{2} \mathrm{H}_{5}\right] t \mathrm{ZR},\left[{ }^{2} \mathrm{H}_{5}\right] t \mathrm{Z} 9 \mathrm{G},\left[{ }^{2} \mathrm{H}_{5}\right] t \mathrm{ZR} 5 \mathrm{MP}$, $\left[{ }^{2} \mathrm{H}_{3}\right] \mathrm{DHZ}, \quad\left[{ }^{2} \mathrm{H}_{3}\right] \mathrm{DHZR}, \quad\left[{ }^{2} \mathrm{H}_{3}\right] \mathrm{DHZ} 9 \mathrm{G}, \quad\left[{ }^{2} \mathrm{H}_{3}\right] \mathrm{DHZR} 5 \mathrm{MP}$ $\left[{ }^{2} \mathrm{H}_{6}\right] \mathrm{iP},\left[{ }^{2} \mathrm{H}_{6}\right] \mathrm{iPR},\left[{ }^{2} \mathrm{H}_{6}\right] \mathrm{iP9G},\left[{ }^{2} \mathrm{H}_{6}\right] \mathrm{iPR} 5 \mathrm{MP},\left[{ }^{2} \mathrm{H}_{5}\right] t \mathrm{ZOG}$, $\left[{ }^{2} \mathrm{H}_{5}\right]$ tZROG, $\left[{ }^{2} \mathrm{H}_{3}\right]$ DHZOG, $\left[{ }^{2} \mathrm{H}_{3}\right]$ DZROG (Olchemim Ltd., Czech Republic). The topolins were analysed using internal deuterium standards for BA $\left(\left[{ }^{2} \mathrm{H}_{7}\right] \mathrm{BA}, \mathrm{BAR}\left(\left[{ }^{2} \mathrm{H}_{7}\right] \mathrm{BAR}\right)\right.$, $\left[{ }^{2} \mathrm{H}_{7}\right] \mathrm{BA} 9 \mathrm{G}$, and $\left.\left[{ }^{2} \mathrm{H}_{7}\right] \mathrm{BAR} 5 \mathrm{MP}\right)$ as no labelled standards were available for the topolins. Thus their values might have an error load which originates from insufficient internal standardization. Also included was an auxin standard of $50000 \mathrm{dpm} 3\left[5(n)-{ }^{3} \mathrm{H}\right] \mathrm{IAA} \quad(0.55-1.11 \mathrm{TBq} / \mathrm{mmol})$ per sample.

Table 1

Parameters used to measure mineral elements by atomic absorption spectroscopy in Salvinia molesta samples

\begin{tabular}{lllll}
\hline Element & Wavelength $(\lambda)(\mathrm{nm})$ & Lamp current $(\mathrm{I})(\mathrm{mA})$ & Slit width $(\mathrm{d})(\mathrm{nm})$ & Flame type \\
\hline $\mathrm{K}$ & 766.5 & Emission & 0.2 & Air-acetylene \\
$\mathrm{Na}$ & 589.0 & Emission & 0.2 & Air-acetylene \\
$\mathrm{Ca}$ & 239.9 & 10.0 & 0.5 & Nitrous oxide-acetylene \\
$\mathrm{Mg}$ & 202.6 & 3.0 & 1.0 & Nitrous oxide-acetylene \\
$\mathrm{Ni}$ & 232.0 & 4.0 & 0.2 & Air-acetylene \\
$\mathrm{Zn}$ & 213.9 & 5.0 & 0.5 & Air-acetylene \\
$\mathrm{Cu}$ & 324.7 & 3.0 & 0.5 & Air-acetylene \\
$\mathrm{Pb}$ & 217.0 & 5.0 & 1.0 & Air-acetylene \\
$\mathrm{Cd}$ & 228.8 & 3.0 & 0.5 & Air-acetylene \\
$\mathrm{Fe}$ & 372.0 & 7.0 & 0.2 & Air-acetylene \\
\hline
\end{tabular}


After $3 \mathrm{~h}$ of extraction, the homogenate was centrifuged $\left(15000 \times g, 4{ }^{\circ} \mathrm{C}\right)$ and the pellets re-extracted. The combined supernatants were concentrated to approximately $1.0 \mathrm{ml}$ under vacuum at $35^{\circ} \mathrm{C}$, diluted to $20 \mathrm{ml}$ with ammonium acetate buffer $(40 \mathrm{mM}, \mathrm{pH} 6.5)$ and purified using a combined DEAESephadex $(1.0 \mathrm{~cm} \times 5.0 \mathrm{~cm})$-octadecylsilica $(0.5 \mathrm{~cm} \times 1.5 \mathrm{~cm})$ column and immunoaffinity chromatography based on generic cytokinin (Faiss et al., 1997) and auxin antibody, respectively. This resulted in three fractions containing (1) the free bases, ribosides and $\mathrm{N}$-glucosides, (2) nucleotides and IAA; (3) $O$ glucosides. Before auxin immunoaffinity chromatography, half of fraction 2 was dissolved in $100 \mu \mathrm{l}$ acidified methanol and methylated using excess of ethereal diazomethane, dried under a stream of nitrogen and dissolved in $500 \mu \mathrm{l}$ of PBS $(50 \mathrm{mM}$, $\mathrm{pH}$ 7.2). The methanolic eluate from all immunoaffinity chromatography columns were evaporated to dryness and dissolved in $75 \mu \mathrm{l}$ of the mobile phase for HPLC analysis. Cytokinin $O$ glucosides and nucleotides were hydrolyzed to free bases and ribosides by action of $\beta$-glucosidase or alkaline phosphatase, respectively before subsequent HPLC-MS analysis (Novák et al., 2003).

The samples were analysed by HPLC (Waters Alliance 2690) linked to a Micromass ZMD 2000 single quadrupole mass spectrometer equipped with an electrospray interface [LC(+)ESMS] and photodiode array detector (Waters PDA 996). Using a post column split of 1:1, the effluent was introduced into an electrospray source (source block temperature $100^{\circ} \mathrm{C}$, desolvation temperature $250^{\circ} \mathrm{C}$, capillary voltage $+3.0 \mathrm{~V}$, cone voltage $20 \mathrm{~V}$ ) and PDA (scanning range $210-300 \mathrm{~nm}$; with $1.2 \mathrm{~nm}$ resolution) and quantitative analysis of the different cytokinins was performed in selective ion recording mode. Quantification was performed by Masslynx software using a standard isotope dilution method. The ratio of endogenous cytokinin to appropriate labelled standard was determined and further used to quantify the level of endogenous compounds in the original extract, according to the known quantity of added internal standard (Novák et al., 2003). The final IAA analysis was done either by a specific competitive ELISA using anti-C1-IAA antibodies and IAA-alkaline phosphatase tracer or by fluorescence HPLC. The determination of the total amount was based on a calibration curve technique and internal standardization using $\left[{ }^{3} \mathrm{H}\right]$ IAA.

\section{Results}

S. molesta grew rapidly, increasing from the initial $0.285 \mathrm{~kg}$ FW to $2.611 \mathrm{~kg}$ air-dried biomass after 31 days growth under the experimental conditions. Decomposition was also rapid with the plant biomass being reduced to approximately a fifth of its original volume within 7 days. The initial air-dried plant mass for composting was $2.00 \mathrm{~kg}$ and a final mass of $31.12 \mathrm{~g} \mathrm{DW}$ was recorded 14 days later.

The mineral content of S. molesta and the composted material are shown in Fig. 1. Concentrations of $\mathrm{Cd}, \mathrm{Pb}$ and $\mathrm{Ni}$ were below the level of detection $\left(<1.5,9.0\right.$ and $4.5 \mathrm{mg} \mathrm{kg}^{-1}$, respectively). There was little change in the $\mathrm{N}$ and $\mathrm{P}$ content of the plant material after 14 days decomposition. However, there was

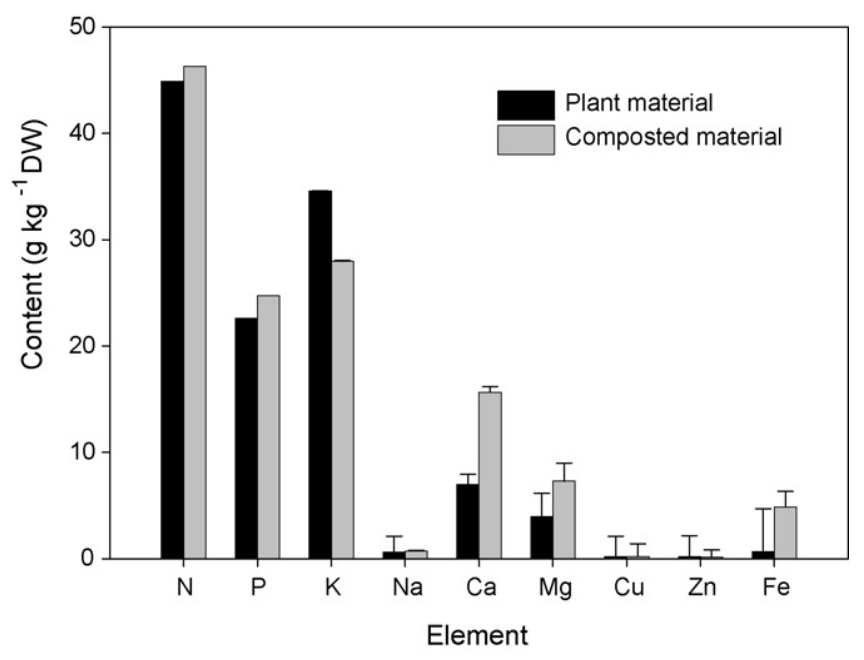

Fig. 1. Mineral element content in Salvinia molesta and material composted for 14 days.

a decrease in the $\mathrm{K}$ content and an increase in the $\mathrm{Ca}, \mathrm{Mg}$ and Fe content with decomposition.

The plant material showed some cytokinin-like activity in the soybean callus bioassay with peaks of activity co-eluting with zeatin, iP and ribotide standards (Fig. 2A). The culture medium (5 l) also showed similar activity (Fig. 2B). The leachate extracts (Fig. 2C-E) were very active with the leachate collected on day 7 showing greater biological activity than the $50 \mu \mathrm{g}^{-1}$ kinetin standard. The composted material also had good activity with a large peak of activity co-eluting with the $O$-glucoside standards to produce cytokinin-like activity equivalent to $10 \mu \mathrm{g} \mathrm{l}^{-1}$ kinetin (Fig. 2F).

The plant material and culture medium had auxin-like rooting activity equivalent to $10^{-4} \mathrm{M}$ IBA (Fig. 3A and B). No activity was measured in the leachate collected on day 0 of the composting experiment (Fig. 3C) while auxin-like activity increased in the leachates collected later during the composting experiment. The leachate collected on day 14 had activity equivalent to $10^{-5} \mathrm{M}$ IBA (Fig. 3E). The composted material showed less auxin-like activity compared to the plant material with activity equivalent to $10^{-5} \mathrm{M}$ IBA (Fig. 3F).

Sixteen isoprenoid cytokinins including $t \mathrm{Z}, c \mathrm{Z}, \mathrm{DHZ}$ and iP forms were detected in $S$. molesta to give a total cytokinin content of $81.62 \mathrm{pmol} \mathrm{g}^{-1}$ DW. Highest concentrations of iP type cytokinins were recorded while very low concentrations of DHZ type cytokinins were detected. No aromatic cytokinins (BA and topolins) were detected in the plant material (Table 2). Only four cytokinins were detected in the culture medium and these occurred at very low concentrations. Three of these cytokinins were free bases ( $t Z, c Z$ and iP; Table 2). Twelve cytokinins were detected in the composted material where the total cytokinin content (67.96 $\left.\mathrm{pmol} \mathrm{g}^{-1} \mathrm{DW}\right)$ was lower than that of the original plant material. This $17 \%$ reduction in cytokinins was mainly due to a decrease in the concentrations of all the $t Z$ type cytokinins, $c$ ZROG, $c$ ZR5MP, iPR and iPR5MP. Concentrations of the DHZ type cytokinins remained constant while there was an increase in the concentrations of $c \mathrm{Z}, c \mathrm{ZOG}$ and $\mathrm{iP}$ in the composted material (Table 2). 

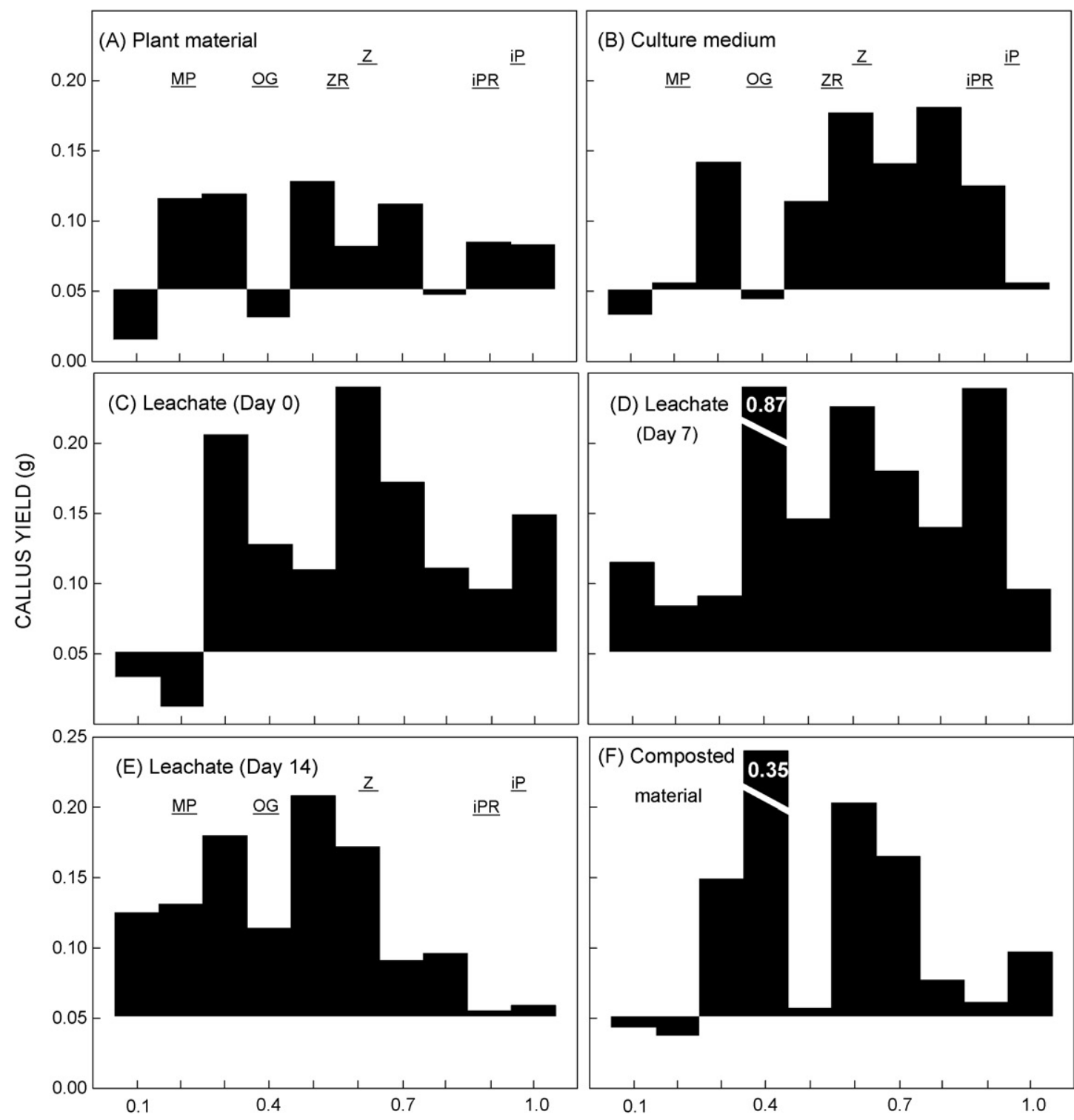

$R_{f}$
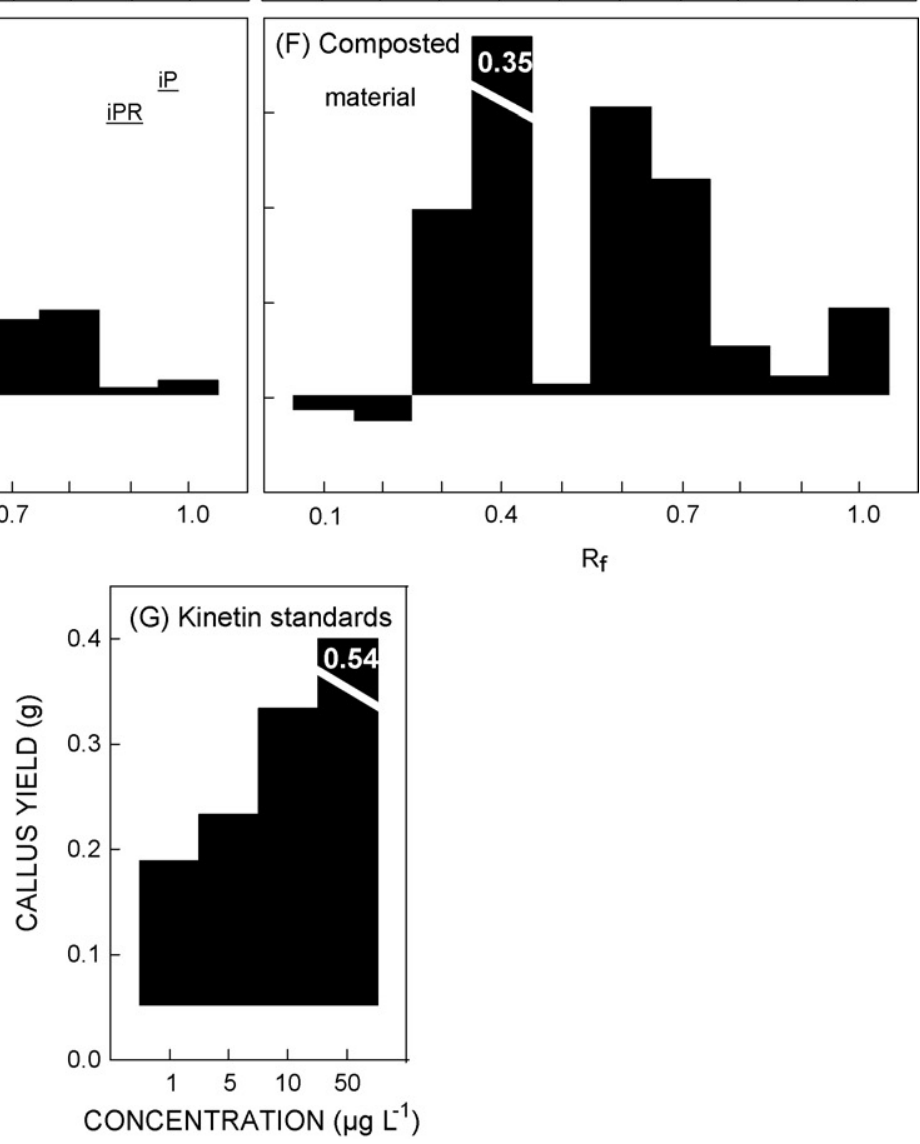

Fig. 2. Cytokinin-like activity detected using the soybean callus bioassay in various Salvinia molesta extracts. $R_{\mathrm{f}}$ values of some authentic cytokinin standards are indicated (MP, monophosphates; OG, $O$-glucosides; ZR, zeatin riboside; Z, zeatin; iPR, isopentenyladenosine; iP, isopentenyladenine). Note the different scale of the $Y$-axis for the kinetin standards $(\mathrm{G})$. 

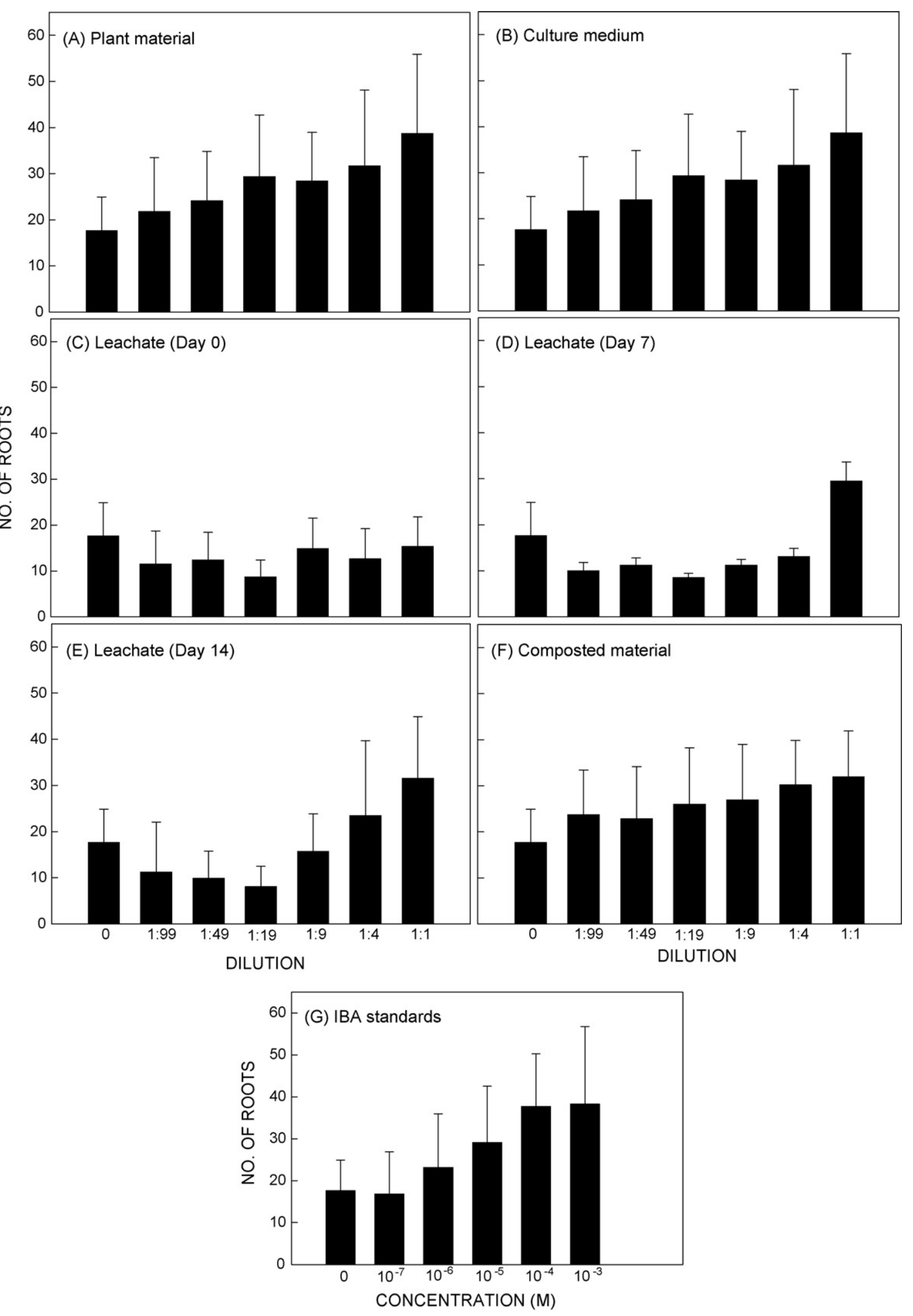

Fig. 3. Auxin-like activity detected using the mungbean rooting bioassay in various Salvinia molesta extracts. 
Table 2

Cytokinins and auxins quantified in the fresh and composted material of Salvinia molesta and the media in which it was grown

\begin{tabular}{|c|c|c|c|}
\hline Hormone & $\begin{array}{l}\text { Plant extract } \\
\left(\mathrm{pmol} \mathrm{g}^{-1} \mathrm{DW}\right)\end{array}$ & $\begin{array}{l}\text { Culture medium } \\
\left(\mathrm{pmol} 500 \mathrm{ml}^{-1}\right)\end{array}$ & $\begin{array}{l}\text { Composted } \\
\text { material } \\
\left(\mathrm{pmol} \mathrm{g}^{-1} \mathrm{DW}\right)\end{array}$ \\
\hline$t \mathrm{Z}$ & $5.98 \pm 0.11$ & $0.55 \pm 0.04$ & $2.85 \pm 0.11$ \\
\hline$t \mathrm{ZR}$ & $4.00 \pm 0.59$ & $<\mathrm{LOD}$ & $0.34 \pm 0.05$ \\
\hline$t \mathrm{ZOG}$ & $5.44 \pm 0.48$ & $<\mathrm{LOD}$ & $1.04 \pm 0.14$ \\
\hline$t \mathrm{ZROG}$ & $3.47 \pm 0.04$ & $<\mathrm{LOD}$ & $<\mathrm{LOD}$ \\
\hline$t \mathrm{ZR} 5 \mathrm{MP}$ & $3.70 \pm 0.65$ & $<\mathrm{LOD}$ & $<\mathrm{LOD}$ \\
\hline Total $t \mathrm{Z}$ derivatives & 22.59 & 0.55 & 4.23 \\
\hline$c \mathrm{Z}$ & $1.44 \pm 0.04$ & $0.57 \pm 0.08$ & $20.02 \pm 1.74$ \\
\hline$c \mathrm{ZR}$ & $3.04 \pm 0.35$ & $<\mathrm{LOD}$ & $2.58 \pm 0.16$ \\
\hline$c \mathrm{ZOG}$ & $1.12 \pm 0.02$ & $<\mathrm{LOD}$ & $9.52 \pm 0.07$ \\
\hline$c \mathrm{ZROG}$ & $5.89 \pm 0.17$ & $<\mathrm{LOD}$ & $1.45 \pm 0.11$ \\
\hline$c$ ZR5MP & $11.73 \pm 0.28$ & $<$ LOD & $<$ LOD \\
\hline Total $c \mathrm{Z}$ derivatives & 23.22 & 0.57 & 33.57 \\
\hline DHZ & $0.84 \pm 0.05$ & $<\mathrm{LOD}$ & $0.63 \pm 0.06$ \\
\hline DHZR & $1.22 \pm 0.03$ & $<$ LOD & $<\mathrm{LOD}$ \\
\hline DHZOG & $1.73 \pm 0.31$ & $<\mathrm{LOD}$ & $1.53 \pm 0.32$ \\
\hline Total DHZ derivatives & 3.79 & - & 2.16 \\
\hline iP & $9.42 \pm 0.98$ & $2.85 \pm 0.33$ & $22.15 \pm 0.80$ \\
\hline iPR & $9.91 \pm 0.69$ & $0.34 \pm 0.05$ & $4.34 \pm 0.05$ \\
\hline iPR5MP & $12.69 \pm 0.22$ & $<\mathrm{LOD}$ & $1.51 \pm 0.18$ \\
\hline Total iP derivatives & 32.02 & 3.19 & 28.00 \\
\hline Total cytokinins & 81.62 & 4.31 & 67.96 \\
\hline Total IAA & $393.6 \pm 37.8$ & $30.8 \pm 4.3$ & $148.1 \pm 12.1$ \\
\hline
\end{tabular}

No aromatic (BA and topolin derivatives) and $-9 \mathrm{G}$ cytokinins were detected. The results are presented as mean \pm S.D. of duplicate measurements. $\angle \mathrm{LOD}=$ below the limit of detection.

A high concentration of IAA was detected in the plant material compared to very low concentrations detected in the culture medium. IAA concentrations were also lower in the composted material with a $62 \%$ loss being recorded when compared to the plant material (Table 2).

\section{Discussion}

S. molesta contained a wide spectrum of mineral elements as found in most plants as well as a number of endogenous cytokinins and IAA. These extracts also had biological activity that enhanced both cell division in the soybean callus bioassay (cytokinin-like activity) and rooting in the mungbean bioassay (auxin-like activity). Cytokinins have previously been reported to occur in ferns. For example, iPR was identified in the fertile fronds of Dryopteris crassirhizoma (Yamane et al., 1983) and Z, ZR, iP and iPR were detected in the fertile fronds of the aquatic Marsilea drummondii (Pilate et al., 1989). The cytokinin complement of $S$. molesta was similar to that found in other lower order plants such as algae and mosses where a literature survey by Auer (1997) found that these groups of plants generally contained mainly $\mathrm{Z}$ and $\mathrm{iP}$ free bases and their respective riboside and ribotide conjugates. Recent advances in the ana- lytical techniques used in plant growth regulator research now enable lower concentrations of compounds to be detected. The present study was able to detect $O$-glucoside derivatives and very low concentrations of DHZ derivatives in S. molesta. Aromatic cytokinins (BA and topolin) were absent or occurred at concentrations below the limit of detection.

Air-dried $S$. molesta underwent rapid decomposition with the plant matter being greatly reduced in biomass within 7 days. There was a rapid release of cytokinin-like and auxin-like compounds with biological activity being detected in the leachate collected after 7 days composting (Figs. 2 and 3). By day 14, there had been a $17 \%$ decrease in cytokinin and $62 \%$ decrease in auxin concentrations found in the plant matter indicating that these metabolites are rapidly released, making them available for uptake from the soil. The increase in the $c \mathrm{Z}$ type cytokinins in the composted material (Table 2) may be due to an increase in the bacteria population. Bacteria contain $c \mathrm{Z}$ type cytokinins that are derived from tRNA (Zažímalová et al., 1999). Using the same composting methods as the present study, visual signs of decomposition were only observed 2 months after composting in manually shredded Gingko biloba leaves. Cytokinin-like compounds were only detected in the leachate collected after 4 months (Arthur et al., 2001). These results highlight the rapid decomposition and release of cytokinins and auxins from $S$. molesta.

The mineral content of $S$. molesta changed after 14 days decomposition with there being an increase in the $\mathrm{Ca}, \mathrm{Mg}$ and Fe content, a decrease in the $\mathrm{K}$ content and little change in the other mineral elements (N, P, Na, Cu and Zn). This suggests that very few nutrients had yet been released into the leachate by day 14. This increase in certain mineral elements may be due to an increase in the bacterial population on the decomposing leaves. Like S. molesta, dried Azolla decomposed within 8-10 days when incorporated into rice paddy soil although it took 5-8 weeks for two thirds of the Azolla's nitrogen content to be released (Lumpkin and Plucknett, 1980). Pretreatment of Azolla filiculoides by heating or air-drying enhanced its effectiveness in improving wheat growth and yield compared to fresh A. filiculoides plants applied directly to the soil. This was attributed to the drying treatments enhancing decomposition rates (Ripley et al., 2003).

The main benefit to using Azolla as a biofertilizer is its nitrogen-fixing ability. However, a comparative study using Azolla microphylla and Sesbania rostrata showed that on a dry weight basis, $S$. rostrata released more nitrogen $\left(\mathrm{NH}_{4}{ }^{+}\right)$than $A$. microphylla, probably owing to the higher lignin content of $A$. microphylla which is known to retard mineralization (Nagarajah et al., 1989). Thus other non-nitrogen-fixing plants with a high productivity and biomass such as $S$. molesta should also be considered as potential biofertilizers.

One major concern with using Azolla as a biofertilizer is the possibility that this practice can promote spore dispersal. Viable spores were found in soils that had been fertilized with A. filiculoides (Ripley et al., 2003). By promoting the use of dried S. molesta, a sterile hybrid, this major concern is nullified. Also, sustained harvesting could help lessen the negative impact of this weed on the environment. 
There is increasing evidence that phytohormones may be recycled through the environment in a similar manner to that of nutrients. In a previous study using S. molesta and A. filiculoides, cytokinin-like activity was detected in the culture medium (Stirk and van Staden, 2003). Similar cytokinin-like activity was obtained in the current study with $S$. molesta although a different purification method was used. Auxin-like activity was also detected in the current study. Compound identification and quantification by analytical techniques confirmed that low concentrations of cytokinins and auxins were present in the culture medium. These results show that $S$. molesta does exude compounds which alter the culture medium in which it is growing and can thus potentially influence the growth of other aquatic plants growing in the same water system.

The results confirm the hypothesis that $S$. molesta can potentially be used as an organic fertilizer. S. molesta undergoes rapid vegetative growth as seen by the rapid doubling time of the plant biomass in the present experiment and thus has a large biomass making it a prolific and productive species. It contains many mineral elements as well as plant hormones (cytokinin and auxins). Once dried, it quickly decomposes so that metabolites such as cytokinins and auxins are available for uptake by crop plants although the release of mineral elements appears to be a slower process. Also, as it is a sterile hybrid, there is no danger of agricultural practices aiding its dispersal. Thus $S$. molesta has great potential as a sustainable environmentally friendly, cheap alternative to agro-chemicals and its use could be promoted amongst small-scale farmers as a way of increasing crop yield while minimizing costs of chemical fertilizers.

\section{Acknowledgements}

The National Research Foundation (South Africa), Czech Ministry of Education (MSM 6198959216, LC06034) and Czech Grant Agency (206/05/0894) are thanked for financial assistance. We wish also to thank Hana Martínková and Petra Amarkorová for excellent technical assistance.

\section{References}

Antanasopoulos, N., 1996. Flame Methods Manual for Atomic Absorption. GBC Science Eq. Pty Ltd., Dandenong, Australia.

Arthur, G.D., Jäger, A.K., van Staden, J., 2001. The release of cytokinin-like compounds from Gingko biloba leaf material during composting. Environ. Exp. Bot. 45, 55-61.

Auer, C.A., 1997. Cytokinin conjugation: recent advances and patterns in plant evolution. Plant Growth Regul. 23, 17-32.

Burrows, J.E., 1990. Southern African Ferns and Fern Allies. Frandsen Publishers, Sandton.
Crouch, I.J., van Staden, J., 1991. Evidence for rooting factors in a seaweed concentrate prepared from Ecklonia maxima. J. Plant Physiol. 137, 319-322.

Crouch, I.J., van Staden, J., 1994. Commercial seaweed products as biostimulants in horticulture. J. Home Consum. Hort. 1, 19-75.

Dobrev, P.I., Kamínek, M., 2002. Fast and efficient separation of cytokinins from auxin and abscisic acid and their purification using mixed-mode solid-phase extraction. J. Chromatogr. A 950, 21-29.

Faiss, M., Zalubilová, J., Strnad, M., Schmülling, T., 1997. Conditional transgenic expression of the ipt gene indicates a function for cytokinins in paracrine signalling in whole tobacco plants. Plant J. 12, 401-415.

Henderson, L., Cilliers, C.J., 2002. Invasive Aquatic Plants Plant Protection Research Institute Handbook No. 16. Paarl Printers, Cape Town.

Hill, M.P., Cilliers, C.J., 1999. Azolla filiculoides Lamarck (Pteridophyta: Azollaceae), its status in South Africa and control. Hydrobiologia 415, 203-206.

Lejeune, A., Cagauan, A., van Hove, C., 1999. Azolla research and development: recent trends and priorities. Symbiosis 27, 333-351.

Lumpkin, T.A., Plucknett, D.L., 1980. Azolla: botany, physiology, and use as a green manure. Econ. Bot. 34, 111-153.

Mansor, M., 1996. Noxious floating weeds of Malaysia. Hydrobiologia 340, $121-125$.

Miller, C.O., 1965. Evidence of the natural occurrence of zeatin and derivative compounds from maize which promote cell division. Proc. Natl. Acad. Sci. U.S.A. 54, 1052-1058.

Nagarajah, S., Neue, H.U., Alberto, M.C.R., 1989. Effect of Sesbania, Azolla and rice straw incorporation on the kinetics of $\mathrm{NH}_{4}, \mathrm{~K}, \mathrm{Fe} \mathrm{Zn}$ and $\mathrm{P}$ in some flooded rice soils. Plant Soil 116, 37-48.

Novák, O., Tarkowski, P., Tarkowska, D., Dolezál, K., Lenobel, R., Strnad, M., 2003. Quantitative analysis of cytokinins in plants by liquid chromatography-single-quadrupole mass-spectrometry. Anal. Chim. Acta 480, 207-218.

Parosa, R., Reszke, E., 1995. Procedures of Dissolution and Digestion of Analytical Samples. Plazmatronika Services S.C., Wroclaw, Poland.

Pedurand, P., Reynaud, P.A., 1987. Do cyanobacteria enhance germination and growth of rice? Plant Soil 101, 235-240.

Pilate, G., Sossountzov, L., Miginiac, E., 1989. Hormone levels and apical dominance in the aquatic fern Marsilea drummondii. A. Br. Plant Physiol. 90, 907-912.

Ripley, B.S., Kiguli, L.N., Barker, N.P., 2003. Azolla filiculoides as a biofertilizer of wheat under dry-land soil conditions. S. Afr. J. Bot. 69, 295-300.

Schelpe, E.A.C.L.E., Anthony, N.C., 1986. Pteridophyta. In: Leistner, O.A. (Ed.), Flora of Southern Africa. Department of Agriculture and Water Supply, Pretoria, pp. 65-68.

Stirk, W.A., van Staden, J., 2003. Occurrence of cytokinin-like compounds in two aquatic ferns and their exudates. Environ. Exp. Bot. 49, 77-85.

Stirk, W.A., Arthur, G.D., Lourens, A.F., Novák, O., Strnad, M., van Staden, J., 2004. Changes in cytokinin and auxin concentrations in seaweed concentrates when stored at an elevated temperature. J. Appl. Phycol. 16, 31-39.

Wagner, G.M., 1997. Azolla: a review of its biology and utilization. Bot. Rev. $63,1-26$.

Yamane, H., Watanaba, M., Satoh, Y., Takahashi, N., Iwatsuki, K., 1983. Identification of cytokinins in two species of Pteriophyte sporophytes. Plant Cell Physiol. 24, 1027-1031.

Zažímalová, E., Kamínek, M., Březinová, A., Motyka, V., 1999. Control of cytokinin biosynthesis and metabolism. In: Hooykaas, P.J.J., Hall, M.A., Libbenga, R.K. (Eds.), Biochemistry and Molecular Biology of Plant Hormones. Elsevier Science B.V., Amsterdam, pp. 141-160. 